\title{
Research Square \\ Experimental study on the reduction effect of pit texture on disassembly damage for interference fit
}

\author{
Dan Zhou \\ Hefei University of Technology \\ YiXu ( $\nabla$ xuyi_hfut@163.com) \\ Xin Gao \\ Hefei University of Technology \\ Hai-Hong Huang \\ Hefei University of Technology
}

Hefei University of Technology https://orcid.org/0000-0001-8863-9965

\section{Original Article}

Keywords: Remanufacturing, Interference fit, Disassembly damage, Surface texture

Posted Date: August 26th, 2020

DOl: https://doi.org/10.21203/rs.3.rs-64107/v1

License: (9) This work is licensed under a Creative Commons Attribution 4.0 International License.

Read Full License 


\section{Title page}

\section{Experimental study on the reduction effect of pit texture on disassembly damage for interference fit}

Dan Zhou, born in 1980, is currently an associate professor of Mechanical Engineering College of Hefei University of technology, China. Her research interests include surface texture.

Tel: +86-133-49296927; E-mail: zhoudan80@126.com

Yi Xu, born in 1996, is currently a master of Mechanical Engineering College of Hefei University of technology, China. Tel: +86-139-66777247; E-mail:xuyi_hfut@163.com

Xin Gao, born in 1993, is a master of Mechanical Engineering College of Hefei University of technology, China.

E-mail: 1970433375@qq.com

Hai-Hong Huang, born in 1980, is currently a professor of Mechanical Engineering College of Hefei University of technology, China.

E-mail: allenhuanghaihong@163.com

Song-Jiang Lv, born in 1984, is currently an engineer of CRRC Nanjing Puzhen Co. Ltd., China

Corresponding author: Dan Zhou E-mail: zhoudan80@126.com 


\section{Experimental study on the reduction effect of pit texture on disassembly damage for interference fit Dan Zhou ${ }^{1}$, Yi Xu ${ }^{1}$, Xin Gao ${ }^{1}$, Hai-Hong Huang ${ }^{1}$, Song-Jiang $\mathbf{L v}^{2}$}

\begin{abstract}
After remanufacturing disassembly, several kinds of friction damages can be found on the mating surface of interference fit. These damages should be repaired and the cost is closely related to the severity of damages. Inspired by the excellent performance of surface texture in wear reduction, 5 shapes of pit array textures are added to the specimens' surface to study their reduction effect of disassembly damage for interference fit. The results of disassembly experiments show that the order of influence of texture parameters on disassembly damage is as follows: equivalent circle diameter of single texture, texture shape and texture surface density. The influence of equivalent circle diameter of single texture and texture shape are obviously more significant than that of texture surface density. The circular texture with a surface density of $30 \%$ and a diameter of $100 \mu \mathrm{m}$ shows an excellent disassembly damage reduction effect. The load-carrying capacity of interference fit with the excellent texture is confirmed by load-carrying capacity experiments. The results show that the load-carrying capacity of the excellent texture surface is increased about $40 \%$ compared with that of without texture.
\end{abstract}

Keywords: Remanufacturing - Interference fit - Disassembly damage $\cdot$ Surface texture

\section{Introduction}

Remanufacturing is a kind of green manufacturing technology which has achieved good social and economic benefits [1] and is widely adopted in automotive [2], construction machinery [3], IT equipment [4] and other fields. In the process of remanufacturing, disassembly is an essential process, which will directly affect the quality and economic benefits of the product [5].

Dan Zhou

zhoudan80@126.com

1 School of Mechanical Engineering, Key Laboratory of Green Design and Manufacturing in Machinery Industry, Hefei University of Technology, Tunxi Road 193, Hefei 230009,China

2 CRRC Nanjing Puzhen Co. Ltd., Longhu Road 5, Nanjing 210031,China
Interference fit is used extensively in the fixed connection of mechanical parts because of its simple structure and super torque transmitting capability [6]. However, the interference fit is difficult to be disassembled because of the high contact pressure on the fitting surface [7].

In order to reduce the difficulty of disassembly, the means of thermal expansion[8], cold contraction[9] or the injection of high-pressure oil into the fitting surface[10] are often used in engineering practice to realize the separation of fitting parts. The key point of these methods is to reduce the contact pressure of fitting surface to separate the parts easily. However, in the operation process, the contact pressure is difficult to be reduced to zero and the matching surface is also difficult to maintain non-contact state especially in the case of with large interference fit. That means the disassembly damage on fitting surface is hard to be avoided.

After remanufacturing disassembly, several kinds of friction damages (e.g. scratching, furrows and material accumulation) often can be found on the mating surface of the parts with interference fit. These damages present a typical evolution process along the direction of disassembly, beginning with scratches, increasing gradually, and finally evolving to furrows and accumulation of materials [11]. Generally, these damages should be repaired and the cost is closely related to the severity of damages.

These damages are subject to the dry friction between fitting surfaces. The degree of damage is closely related to the properties of material, surface state and contact pressure [12]. For remanufacturing, the material and the contact pressure between the mating surfaces of fitting parts is difficult to be changed, so it can only be explored from the surface state. In recent years, surface texture [13], as a surface treatment technology, has exhibited a favorable tribological performance in piston rings [14], cutting tools [15], mechanical seals [16], and biomedical application [17]. Inspired by the fact that pit array textures has good anti-wear effect under the condition of dry friction [18], 5 different shapes of pit array textures are created on the specimens' surface, and the reduction effect of texture on the disassembly damage of interference fit is 
observed by orthogonal experiment. From the $\mathrm{L}_{25}\left(5^{4}\right)$

orthogonal experiments, a kind of pit array texture with great disassembly damage reduction effect is determined.

\section{Experiment details}

\subsection{Experiment model of interference fit}

Large interference fit is commonly used in heavy load cases with high-speed rotation. As shown in Fig.1, torque $T$ is transmitted by the static friction torque between the fitting surfaces of cylinder and shaft. And the maximum static friction torque $M_{f}$ can be calculated as:

$$
M_{f}=\frac{d_{f}}{2} F_{S}=\frac{d_{f}}{2} \mu P S
$$

$d_{f}$ is the diameter of the fitting surface, $\mathrm{mm} ; F_{s}$ is the maximum static friction force on fitting surface, $\mathrm{N} ; \mu$ is the maximum static friction coefficient of fitting surface; $P$ is the nominal contact pressure on fitting surface, $\mathrm{MPa} ; S$ is the nominal area of fitting surface, $\mathrm{mm}^{2}$. Generally, $T<M_{f}$ is the prerequisite that interference fit can work properly. When $P$, $\mathrm{S}$ and $d_{f}$ are invariant, the load-carrying capacity of interference fit is determined by $\mu$. So, the key point for the specimens of interference-fit experiment is to obtain a similar friction state on fitting surface, and the nominal contact pressure $P$ and static friction coefficient $\mu$ on the fitting surface can be effectively controlled.

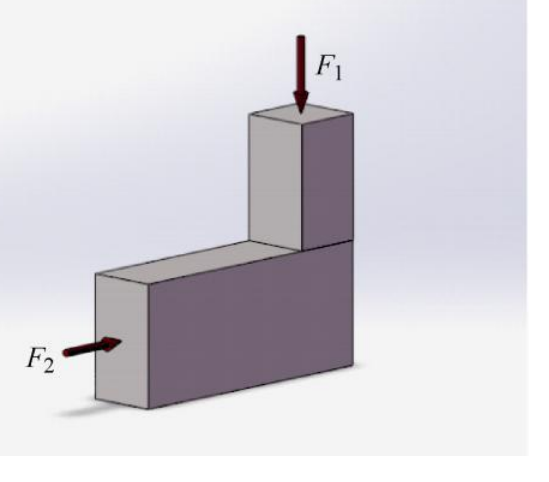

a) Disassembly damage simulation experiment

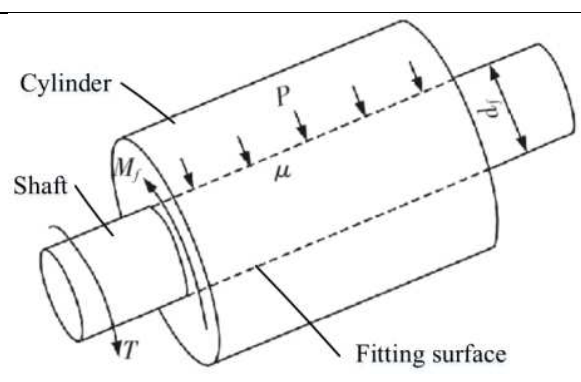

Figure 1 Interference fit model

In the following experiments, a pair of cuboid specimens is adopted as shown in Fig. 2. The contact surface between upper specimen and lower specimen simulates the fitting surface. The contact pressure $P$ can be controlled by the vertical force $F_{1}$. And the friction coefficient $\mu$ on the contact surface of the specimens can be adjusted by the state of surface topography. In order to decrease the manufacturing difficulty, the contact surfaces of specimens are simplified as planes, which are different from the actual cylindrical surfaces of interference-fitting parts. But this difference doesn't affect the friction state between fitting surfaces. The relationship between $P, \mu, S$ and $M_{f}$ does not change, and the friction damage on contact surface caused by the relative sliding between specimens is similar with the friction damage on fitting surface because of disassembly process.

The specific information of specimens is described in Table 1 . The area of contact surface is $10 \mathrm{~mm} \times 10 \mathrm{~mm}$. KMN and $40 \mathrm{CrNiMo} 7$ are select as the materials for upper and lower specimen which are common used for impeller and spindle of centrifugal compressor. The shrink range between the impeller and spindle is often very large, sometimes up to $1.5 \%$ of the diameter of fitting surface[19].

Changing the installation mode of lower specimen, the simulation experiment of disassembly damage and the test of load-carrying capacity can be realized respectively.

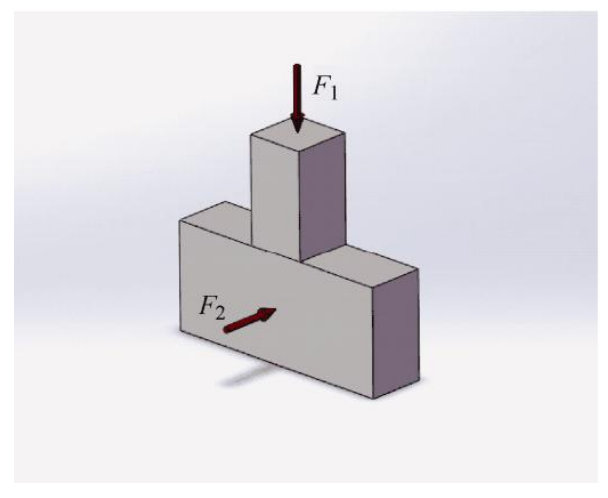

b) Load-carrying capacity simulation experiment

Figure 2 Simplified experiment model of interference fit (contact area: $10 \mathrm{~mm} \times 10 \mathrm{~mm} ; F_{1}$-the vertical force applied by experiment platform; $F_{2}$-the horizontal force applied by experiment platform) 
Table 1 Materials and properties of specimens

\begin{tabular}{cccccc}
\hline Specimen & Material & $\begin{array}{c}\text { Specimen size } \\
/ \mathrm{mm}\end{array}$ & $\begin{array}{c}\text { Modulus of } \\
\text { elasticity } \\
/ \mathrm{GPa}\end{array}$ & $\begin{array}{c}\text { Yield strength } \\
/ \mathrm{MPa}\end{array}$ & $\begin{array}{c}\text { Hardness } \\
/ \mathrm{HRC}\end{array}$ \\
\hline Upper specimen & KMN & $10 \times 10 \times 18$ & 281 & 1006 & $31 \sim 35$ \\
Lower specimen & $40 \mathrm{CrNiMo} 7$ & $10 \times 40 \times 18$ & 209 & 800 & $29 \sim 32$ \\
\hline
\end{tabular}

As shown in Fig.2 a), the contact pressure on the surface is simulated by the force of the $F_{1}$ and the disassembly force is simulated by $F_{2}$. During the disassembly damage simulation experiment, the lower specimen will be moved by $F_{2}$. When the moving distance reaches $30 \mathrm{~mm}$ or the lower specimen is stuck because of surface damage and unable to move, the experiment ends. After the experiments, the surface damage of the specimens will be observed by Trimos-CL3 three-dimensional surface topography instrument and Optika XDS-3MET microscope.

As shown in Fig. 2 b), the lower specimen is rotated $90^{\circ}$ to simulate the direction of static friction force between the actual parts, which is same as the load-carrying direction. The contact pressure on the fitting surface during service is simulated by $F_{1}$. The load to be carried by the interference fit is simulated by $F_{2}$. In the experiment, $F_{2}$ is gradually increased until a relative displacement occurs between the two specimens. At this point, $F_{2}$ exceeds the load-carrying capacity of the interference fit and the joint fails; the load-carrying capacity experiment is completed. The ratio of $F_{2}$ to $F_{1}$ is the maximum static friction coefficient $(\mu)$ which can be used as a measurement for the load-carrying capacity of interference fit.

\subsection{Specimens processing}

Several kinds of pit array texture are manufactured on the surface of lower specimens by HGTECH LSF20D fiber laser marking machine. The following parameters are employed for the texture processing: $1064 \mathrm{~nm}$ laser wavelength, $4 \mathrm{~W}$ average power, $16.9851 \mathrm{~W} \cdot \mathrm{s} / \mathrm{cm}^{2}$ power density, $500 \mathrm{~mm} / \mathrm{s}$ scanning speed, $20 \mathrm{kHz}$ repetition rate, using a circular beam spot of $0.06 \mathrm{~mm}$ diameter. The upper specimens are not textured.

After the texture processed, the burr around pit edge is removed by $1000 \#$ sandpaper. When the non-textured contrast experiment is carried out, the surfaces of the non-textured lower specimens are treated with the same process. Before the experiment, the upper and lower specimens are cleaned by acetone. After clamped in the platform of experiment, the specimens are cleaned one more time by alcohol. And when the surface goes dry, the experiment can be started.

\subsection{Experiment Platform}

The experiment platform is shown in Fig. 3, which adopts a four-guide-pillars structure with three plates in the horizontal direction. The upper specimen is fixed by the upper fixture under the middle plate, which can move up and down along the guide pillars under the action of vertical hydraulic cylinder. The load of the vertical hydraulic cylinder is controlled by the control system to obtain the required force $F_{1}$. The lower specimen is fixed in the lower fixture, which can move along the linear motion rolling guide on the lower plate under the action of horizontal hydraulic cylinder. The load of the horizontal hydraulic cylinder is also controlled by the control system to apply $F_{2}$. The real-time data of the load value and displacement of the two hydraulic cylinders are recorded by sensors.

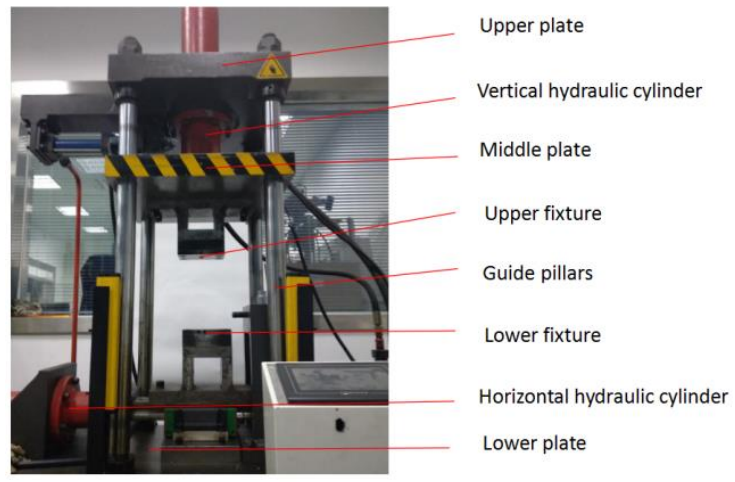

Figure 3 Experiment platform

\subsection{Disassembly experiment scheme}

To study the damage reduction effect of surface texture for disassembly, the orthogonal experiment method [20-21] is adopted, and 3 factors and 5 levels are chosen for the disassembly experiments. As shown in Table 2, the factors include: equivalent circle diameter of single texture (Factor A), dimple density of surface texture (Factor B), and texture shape (Factor C). In the experiments, 5 different shapes of texture are considered, and their geometric dimensions are described by the Factor A (equivalent circle diameter of single texture). The equivalent circle diameter $\left(D_{e}\right)$ describes the size of single pit. For the textures with the same value of $D_{e}$, their areas of single pit are all equal to the area of the circle with the diameter of $D_{e}$. The dimple density of texture surface describes the ratio of pit area to total surface area. 


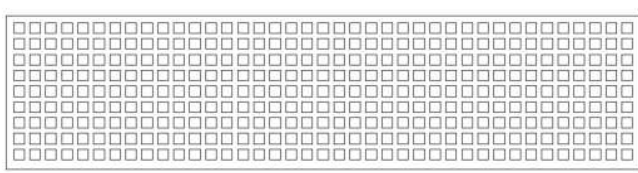

( a ) Square texture

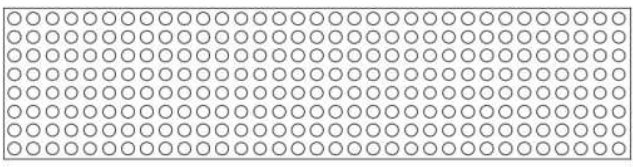

( b ) Circular texture

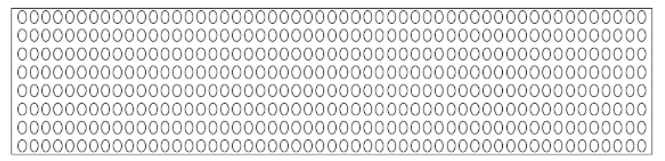

( c ) Elliptical-1 texture

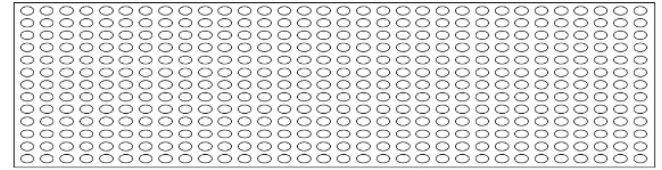

(d ) Elliptical-2 texture

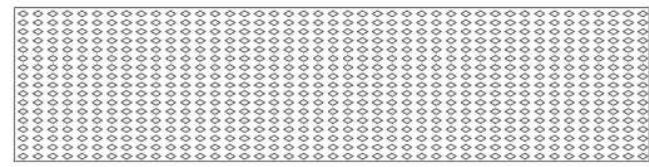

The shapes of texture are shown in Fig.4, including square, circular, elliptical-1, elliptical-2 and rhombic, which include most kinds of conventional geometries other than triangle. The triangle is not involved in the experiment because the three angles of triangle limit the effective size of particle collection for single texture pit. Thus, its effect of damage reduction will not exceed that of the shaped adopted in the experiment[22].

The center distances of pits on a textured specimen are equidistant in the direction of row and column. And the depth of these textures is fixed as $40 \mu \mathrm{m}$. For the two kinds of ellipses (or the rhombus), their length ratio of short axis (or diagonal) to long axis (or diagonal) is 0.618.

In the disassembly experiment, $F_{1}$ is set as $12.5 \mathrm{KN}$ (the nominal contact pressure $P$ between specimens is equal to 125 $\mathrm{MPa}$ ), and the degree of disassembly damage will be evaluated by the value of damage comprehensively evaluation $(Q)$ through entropy method [8]. The bigger value of $Q$ means the greater damage. 6 parameters, $S_{v}, S_{p}, S_{q}, S_{t r}, V_{m p}$, and $S_{a}$ are selected as the indexes for entropy evaluation from ISO25178 [23]. The physical meanings of each index are as follows:

$S_{v}$ : Maximum depth of material surface.

$S_{p}$ : Maximum height of material surface.

$S_{q}$ : Root mean square deviation of material surface.

$S_{t r}:$ Texture aspect ratio.

$V_{m p}$ : Average surface volume of material.

$S_{a}$ : The arithmetic mean of the surface height of the material.

( e ) Rhombic texture

Figure 4 Schematic diagram of the texture of different shape

Table 2 Factors and levels of disassembly damage simulation experiment

Factor A

Factor B

Factor C

Level

Equivalent circle diameter of single texture $(\mu \mathrm{m}) \quad$ Texture surface density $(\%) \quad$ Texture shape

\begin{tabular}{lccc}
\hline 1 & 50 & $10 \%$ & Square \\
2 & 100 & $15 \%$ & Circular \\
3 & 150 & $20 \%$ & Elliptical-1 \\
4 & 200 & $25 \%$ & Elliptical-2 \\
5 & 250 & $30 \%$ & Rhombic \\
\hline
\end{tabular}

\section{Results and Analysis}

\subsection{Experiment Result and Range Analysis}

Orthogonal experiment can distinguish the influence degree of factors on the experiment results and draw out the 
excellent parameters scheme with fewer times of experiment. In the disassembly experiment, a $\mathrm{L}_{25}\left(5^{4}\right)$ orthogonal table is adopt, which contents 25 kinds of parameter scheme. Each scheme is carried out once, and the final comprehensive evaluation values of disassembly damage (Q) are shown in Table 3.

Range analysis is used to evaluate the effect of each factor on damage reduction. And the results are shown in Table 3. $\bar{K}_{\iota}$ is the mean value of $Q$ for level $i(i=1,2,3,4,5)$ of factor (A, B or C). $R$ is the range of $\bar{K}_{l}$. According to the value of $R$, the influence order of factors on the disassembly damage is found as follows: Factor A (equivalent circle diameter of single texture) $>$ Factor C (texture shape) $>$ Factor B (texture surface density).

Since the smaller $Q$ represents the smaller disassembly damage, the factors in the excellent scheme should take the levels with the minimum value of $\bar{K}_{l}$, which is $\mathrm{A}_{2} \mathrm{~B}_{5} \mathrm{C}_{2}$. And the texture described by this scheme is a kind of circular texture with a surface density of $30 \%$ and a diameter of $100 \mu \mathrm{m}$. But this scheme dose not exit in the orthogonal table. So, its reduction effect of disassembly damage needs to be verified, and the relevant content is described in 3.2.

Table 3 Experiments result and range analysis

\begin{tabular}{|c|c|c|c|c|c|}
\hline No. & Parameter scheme & $Q$ & No. & Parameter scheme & $Q$ \\
\hline 1 & $\mathrm{~A}_{1} \mathrm{~B}_{1} \mathrm{C}_{1}$ & 0.63 & 14 & $\mathrm{~A}_{3} \mathrm{~B}_{4} \mathrm{C}_{1}$ & 0.54 \\
\hline 2 & $\mathrm{~A}_{1} \mathrm{~B}_{2} \mathrm{C}_{2}$ & 0.48 & 15 & $\mathrm{~A}_{3} \mathrm{~B}_{5} \mathrm{C}_{2}$ & 0.25 \\
\hline 3 & $\mathrm{~A}_{1} \mathrm{~B}_{3} \mathrm{C}_{3}$ & 0.52 & 16 & $\mathrm{~A}_{4} \mathrm{~B}_{1} \mathrm{C}_{4}$ & 0.61 \\
\hline 4 & $\mathrm{~A}_{1} \mathrm{~B}_{4} \mathrm{C}_{4}$ & 0.45 & 17 & $\mathrm{~A}_{4} \mathrm{~B}_{2} \mathrm{C}_{5}$ & 0.78 \\
\hline 5 & $\mathrm{~A}_{1} \mathrm{~B}_{5} \mathrm{C}_{5}$ & 0.60 & 18 & $\mathrm{~A}_{4} \mathrm{~B}_{3} \mathrm{C}_{1}$ & 0.76 \\
\hline 6 & $\mathrm{~A}_{2} \mathrm{~B}_{1} \mathrm{C}_{2}$ & 0.34 & 19 & $\mathrm{~A}_{4} \mathrm{~B}_{4} \mathrm{C}_{2}$ & 0.44 \\
\hline 7 & $\mathrm{~A}_{2} \mathrm{~B}_{2} \mathrm{C}_{3}$ & 0.36 & 20 & $\mathrm{~A}_{4} \mathrm{~B}_{5} \mathrm{C}_{3}$ & 0.58 \\
\hline 8 & $\mathrm{~A}_{2} \mathrm{~B}_{3} \mathrm{C}_{4}$ & 0.28 & 21 & $\mathrm{~A}_{5} \mathrm{~B}_{1} \mathrm{C}_{5}$ & 1.13 \\
\hline 9 & $\mathrm{~A}_{2} \mathrm{~B}_{4} \mathrm{C}_{5}$ & 0.55 & 22 & $\mathrm{~A}_{5} \mathrm{~B}_{2} \mathrm{C}_{1}$ & 1.43 \\
\hline 10 & $\mathrm{~A}_{2} \mathrm{~B}_{5} \mathrm{C}_{1}$ & 0.45 & 23 & $\mathrm{~A}_{5} \mathrm{~B}_{3} \mathrm{C}_{2}$ & 0.65 \\
\hline 11 & $\mathrm{~A}_{3} \mathrm{~B}_{1} \mathrm{C}_{3}$ & 0.46 & 24 & $\mathrm{~A}_{5} \mathrm{~B}_{4} \mathrm{C}_{3}$ & 0.82 \\
\hline 12 & $\mathrm{~A}_{3} \mathrm{~B}_{2} \mathrm{C}_{4}$ & 0.30 & 25 & $\mathrm{~A}_{5} \mathrm{~B}_{5} \mathrm{C}_{4}$ & 0.73 \\
\hline 13 & $\mathrm{~A}_{3} \mathrm{~B}_{3} \mathrm{C}_{5}$ & 0.58 & & & \\
\hline \multicolumn{4}{|c|}{ Factor A } & Factor B & Factor C \\
\hline \multicolumn{2}{|r|}{$\overline{K_{1}}$} & \multicolumn{2}{|c|}{0.54} & 0.63 & 0.76 \\
\hline \multicolumn{2}{|r|}{$\overline{K_{2}}$} & \multicolumn{2}{|c|}{$\underline{0.40}$} & 0.67 & $\underline{0.43}$ \\
\hline \multicolumn{2}{|r|}{$\overline{K_{3}}$} & \multicolumn{2}{|c|}{0.42} & 0.56 & 0.55 \\
\hline \multicolumn{2}{|r|}{$\overline{K_{4}}$} & \multicolumn{2}{|c|}{0.63} & 0.56 & 0.47 \\
\hline
\end{tabular}




$\begin{array}{lccc}\overline{K_{5}} & 0.95 & \underline{0.52} & 0.73 \\ R & 0.55 & 0.15 & 0.33\end{array}$

Factor influence order

Excellent scheme
$\mathrm{A}>\mathrm{C}>\mathrm{B}$

$\mathrm{A}_{2} \mathrm{~B}_{5} \mathrm{C}_{2}$

\subsection{Verification of damage reduction effect for the excellent texture}

To verify the damage reduction effect of excellent texture scheme (circular texture with a surface density of $30 \%$ and a diameter of $100 \mu \mathrm{m})$, a group of comparative experiments on the disassembly of excellent textured and non-textured specimens are carried out. The material of specimens is same as the previous experiments and the value of $F_{1}$ is set as $12.5 \mathrm{KN}(P=125 \mathrm{MPa})$. The surface topographies and surface parameters of the specimens after disassembly are shown in Fig.5 and Table 4, which are measured by Trimos-CL3 three-dimensional surface topography instrument.

As shown in Fig.5, the disassembly damage of the non-textured specimen is much greater. There are several furrows and adhesion accumulation damage on it, but only a few small scratches on the textured surface. In Fig.5 a), the picture is mainly composed of red and yellow regions. The yellow regions show the existence of pit texture; and the lines in the red area represent the scratches formed by disassembly. In Fig.6 b), according to the height ruler, it can be estimated that the height of the adhesion accumulation damage is about $100 \sim 600 \mu \mathrm{m}$, and the depth of the furrows is about $100 \sim 300 \mu \mathrm{m}$.

As shown in Table 4, the damage evaluation value $(Q)$ of the excellent textured surface is 0.25 , which is much smaller than that of the non-textured surface. This shows that the excellent texture has a positive effect on the reduction of surface damage.

In addition, the $Q$ value of the excellent texture scheme is smaller than that of most schemes in Table 3 except for the No. 15 scheme $\left(A_{3} B_{5} C_{2}\right)$, whose value is also 0.25 . The difference between No. 15 scheme and excellent scheme is that the value of factor A (Equivalent circle diameter of single texture) is $150 \mu \mathrm{m}$, which is $50 \mu \mathrm{m}$ larger than the latter. And the cause of this phenomenon is described in 3.3.

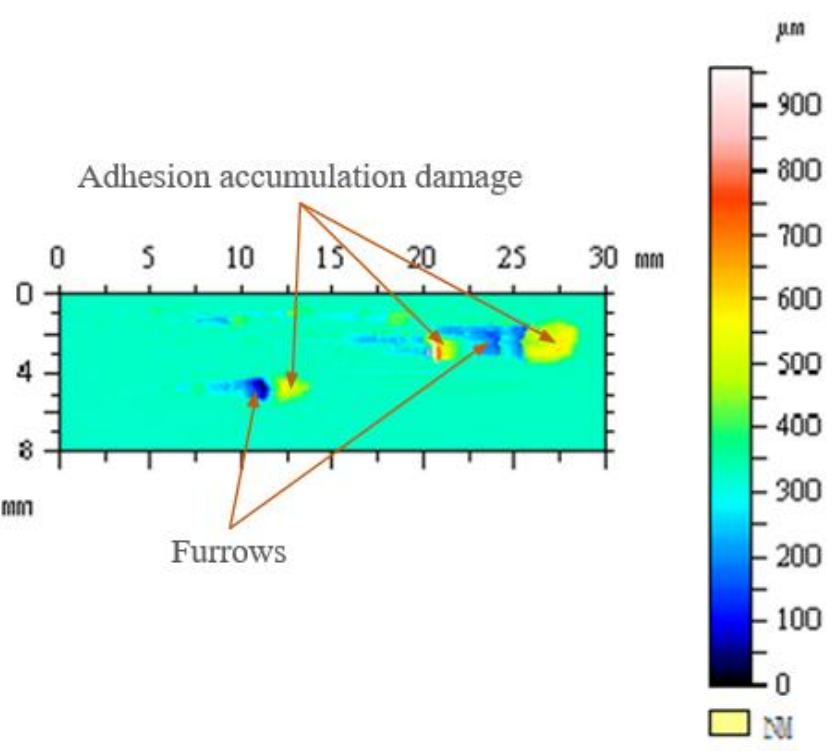

(b) Non-textured specimen after once disassembly

(a) Excellent textured specimen after once disassembly

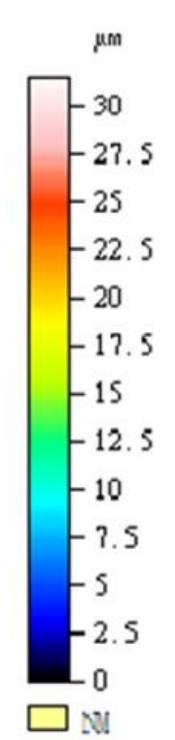

Figure 5 Surface topography image of disassembly damage

Table 4 Surface topography parameters of disassembly damage

\begin{tabular}{cccccccc}
\hline & $S_{v} / \mu \mathrm{m}$ & $S_{p} / \mu \mathrm{m}$ & $S_{q} / \mu \mathrm{m}$ & $S_{t r}$ & $V_{m p} /\left(\mathrm{mm}^{3} / \mathrm{mm}^{2}\right)$ & $S_{a} / \mu \mathrm{m}$ & $Q$ \\
\hline Non-textured & 324 & 628 & 41.1 & 0.807 & 0.00616 & 17.3 & 10.67 \\
Excellent textured & 25.50 & 5.98 & 1.06 & 0.015 & 0.000016 & 0.50 & 0.25
\end{tabular}




\subsection{Reduction Mechanism of Disassembly Damage}

The disassembly damage of interference fit comes from the dry friction between the parts' fitting surfaces caused by the disassembly movement. As literatures shown, surface texture can effectively reduce the dry friction damage is mainly because of its perfect ability of abrasive particle collection[23]. This is also the main reason why the textured surface can significantly reduce the disassembly damage for the interference fit.

The particle collection capacity of texture is mainly affected by two aspects, the total particle collection capacity of textured surface and the effective collection size of single texture pit. Besides the particle collection capacity, for the textured surface, the severity of disassembly damage is also affected by the damage formation and evolution probability on the part of surface without pits.

Fig.6 shows the relationships between factors and comprehensive evaluation value of disassembly damage $(Q)$ according to the range analysis data in Table 3 . In the range of $10 \%$ to $30 \%$ of texture density, the value of $Q$ has a decreasing trend as the texture surface density increased (Fig.6a). It is because that the total volume of pits on the textured surface is increased as the texture surface density increased. Thus the texture pits can collect more particles, and the disassembly damage is getting lower.

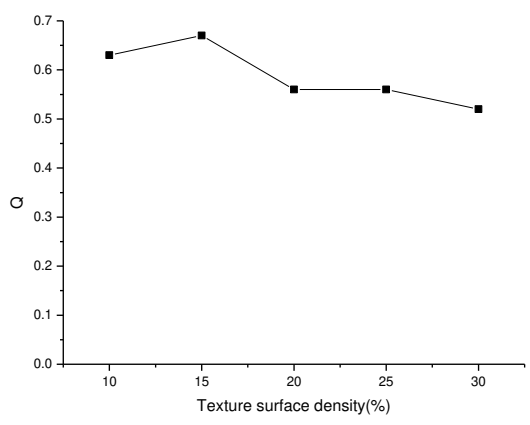

(a) Variation of $Q$ with texture surface density

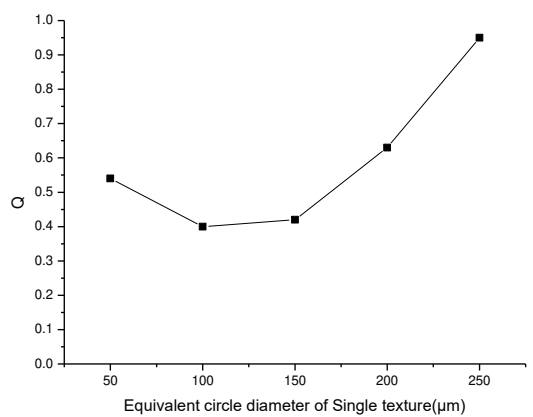

(b) Variation of $Q$ with the equivalent circle diameter of single texture

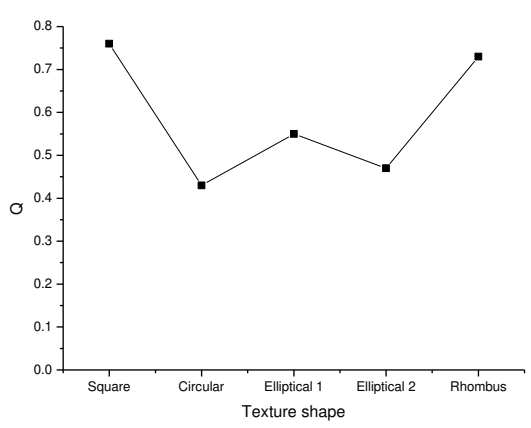

(c) Variation of $Q$ with the texture shape

Figure 6 Variation of comprehensive evaluation value of disassembly damage $(Q)$ with 3 factors

In the range of $50 \mu \mathrm{m}$ to $250 \mu \mathrm{m}$ of equivalent circle diameter, the value of $Q$ decreases first and then increases. The diameter $100 \mu \mathrm{m}$ shows a perfect ability of damage reduction (Fig.6b). Among the 25 kinds of parameter scheme, the reduction effect of diameter $50 \mu \mathrm{m}$ is not satisfactory. The reason is that its effective collection size of single texture does not meet the requirement for particle collection. And the textures with diameters of $200 \mu \mathrm{m}$ and $250 \mu \mathrm{m}$ also having unsatisfactory damage reduction effect is mainly due to their higher damage formation and evolution probability in the area without pits.

As Fig. 7 shown, textured surface consists of two kinds of zone, the pits zone and the without pits zone. Dry friction happens in the zones without pits during the disassembly process. The particles in the area of non-textured row cannot be captured by pits, and the disassembly damage is more likely to occur and become serious as the disassembly distance increases. And in the textured row, the occurrence and evolution of disassembly damage is also emerged on the part of surface without pits, but the evolution process of damage is often interrupted when the particles are captured by the pits. Therefore, for a texture unit, the severity of disassembly damage is closely related to the area of without pits zone in the non-textured $\operatorname{row}\left(S_{n}\right)$ and the area of without pits zone in the textured row $\left(S_{m}\right)$. Between them, $S_{n}$ has a more significant influence on the degree of disassembly damage. Taking the circular texture as an example, the values of $S_{n}$ and $S_{m}$ can be calculated by:

$$
\begin{gathered}
S_{n}=n \times L=\left(\frac{1}{2} \sqrt{\frac{\pi}{C}}-1\right) \cdot D_{e} \times \frac{1}{2} \sqrt{\frac{\pi}{C}} D_{e}=\left(\frac{\pi}{4 C}-\frac{1}{2} \sqrt{\frac{\pi}{C}}\right) D_{e}{ }^{2} \\
s_{m}=L \times D_{e}-\pi \cdot \frac{D_{e}{ }^{2}}{4}=\left(\frac{1}{2} \sqrt{\frac{\pi}{C}}-\frac{1}{4} \pi\right) D_{e}{ }^{2}
\end{gathered}
$$

Where $n$ is the width of non-textured row, $\mu \mathrm{m} ; L$ is the size of texture unit, $\mu \mathrm{m} ; C$ is the texture surface density; $D_{e}$ is the 
equivalent circle diameter of single pit, $\mu \mathrm{m}$.

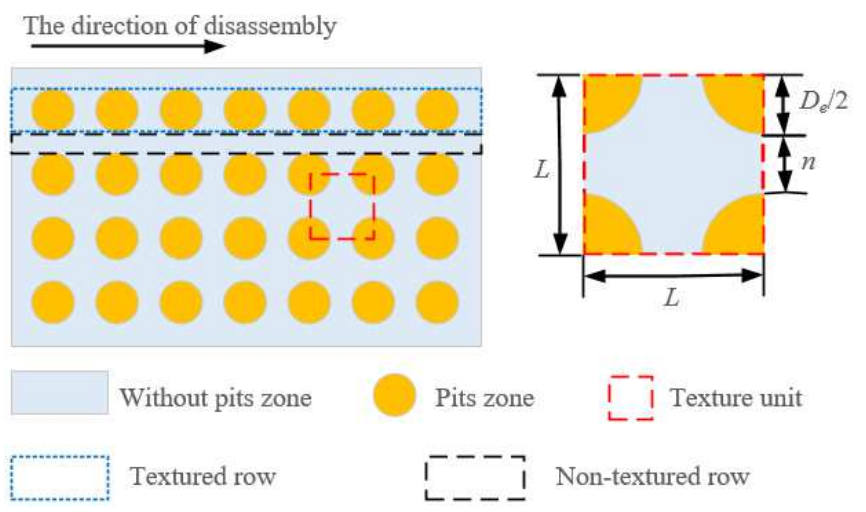

Figure 7 Diagram of textured surface and texture unit (Taking the circular texture as an example)

The values of $S_{n}$ and $S_{m}$ of other texture shapes also can be calculated according to their geometric characteristics. Table 5 shows the calculated results of the 25 texture schemes in Table 3. And the mean value $\bar{K}_{l}(i=1,2,3,4,5)$ of $S_{n}$ and $S_{m}$ for the
5 levels $(50 \mu \mathrm{m}, 100 \mu \mathrm{m}, 150 \mu \mathrm{m}, 200 \mu \mathrm{m}, 250 \mu \mathrm{m})$ of Factor A (equivalent circle diameter of single texture) is described at the bottom of Table 5, which show that the texture with a larger diameter has larger values of $S_{n}$ and $S_{m}$. This is why the disassembly reduction effect of texture with a diameter $200 \mu \mathrm{m}$ or $250 \mu \mathrm{m}$ is lower than the texture with a diameter $100 \mu \mathrm{m}$.

In addition, although the mean values of $S_{n}$ and $S_{m}$ for the diameter $150 \mu \mathrm{m}$ exceeds the value for the diameter $100 \mu \mathrm{m}$ many, the experiment results show that the disassembly damage reduction effect of diameter $150 \mu \mathrm{m}$ and $100 \mu \mathrm{m}$ is very close(Fig. 6b), which is mainly due to the fact that the effective collection size of single pit of the texture with diameter $150 \mu \mathrm{m}$ is larger than that of diameter $100 \mu \mathrm{m}$, so that the poor damage reduction effect is partially improved. That is why the $Q$ value of No. 15 scheme is much closed to the excellent texture scheme described in 3.2 .

Table $5 S_{n}$ and $S_{m}$ of the 25 texture schemes in Table 3 and their mean values for the 5 levels of Factor A

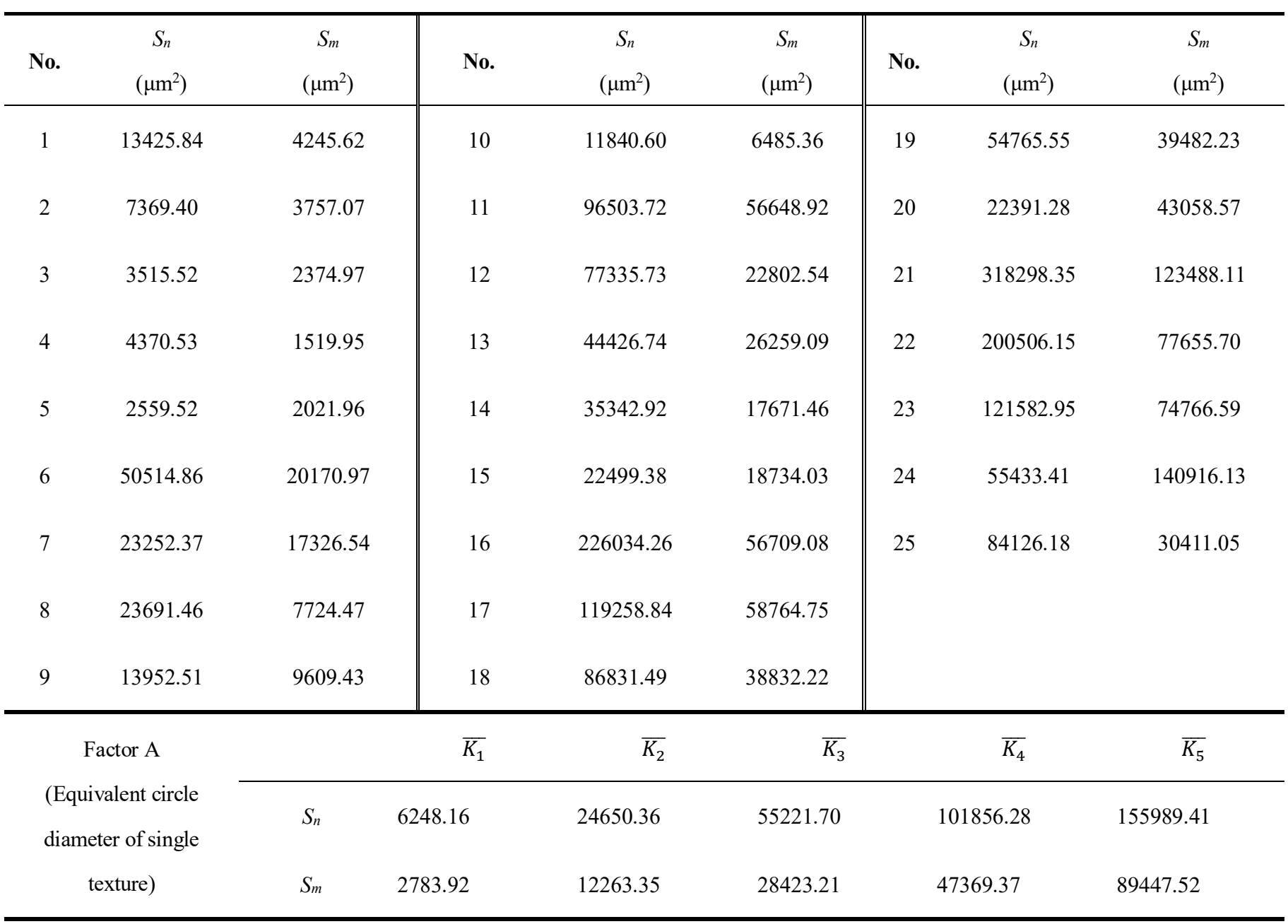

Table 6 Values and the ordinal number of indexes for the 5 levels of Factor C 


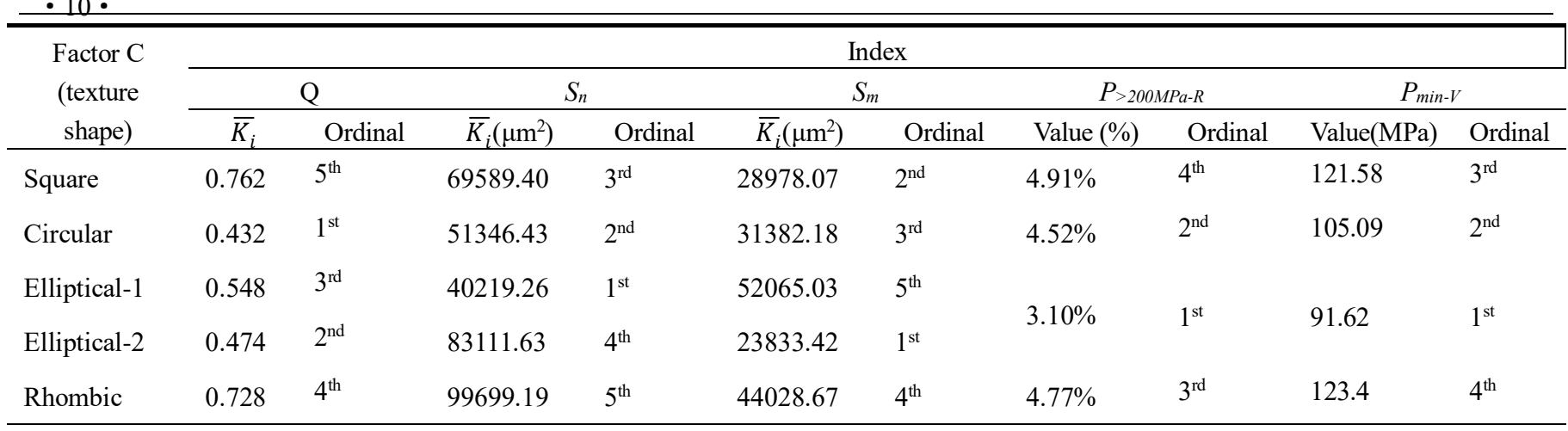

Note:

1) The mean values $\bar{K}_{i}$ of $Q$ come from the data of Table 3;

2) The mean values $\bar{K}_{i}$ of $S_{n}$ and $S_{m}$ are calculated according the data with the same level of Factor C in Table 5;

3) $P>200 \mathrm{MPa}-R$ is the area ratio of the surface contact pressure greater than $200 \mathrm{MPa}$ on the surface of texture units under $100 \mathrm{MPa}$ load, and these units' texture surface density is $30 \%$ and the equivalent circle diameter is $100 \mu \mathrm{m}$;

4) $P_{\min -V}$ is the minimum contact pressure on the surface of texture units under $100 \mathrm{MPa}$ load, and these units' texture surface density is $30 \%$ and the equivalent circle diameter is $100 \mu \mathrm{m}$.

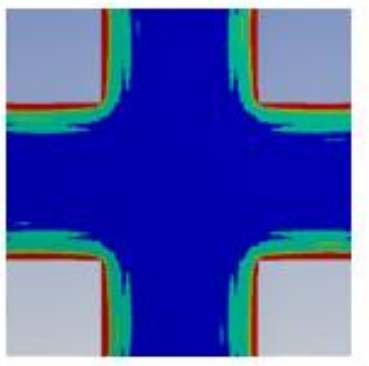

(a)

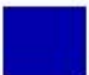

Below140MPa

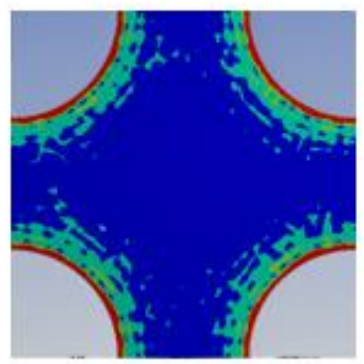

(b)

$140 \mathrm{MPa}-170 \mathrm{MPa}$

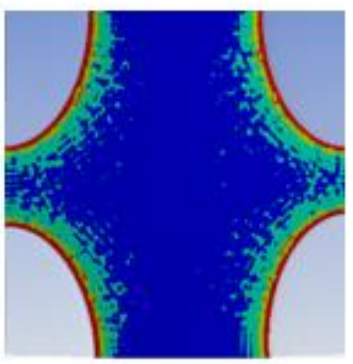

(c)

$170 \mathrm{MPa}-200 \mathrm{MPa}$

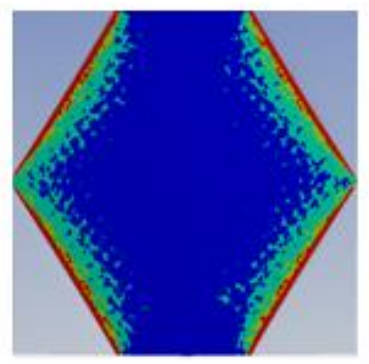

(d)

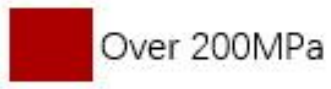

Figure 8 Contact pressure on the surface of texture units ( $\mathrm{a}$ - Square texture unit; $\mathrm{b}$ - Circular texture unit; $\mathrm{c}$ - Elliptical texture unit; $\mathrm{d}$ Rhombic texture unit)

The above explains the influence of Factor A (Equivalent circle diameter of single texture) and Factor B (Texture surface density) on the disassembly damage reduction ability of pit texture. As for Factors C(shown in Fig.6c), Circular and Elliptical-2 have better damage reduction effect. But for the $S_{n}$ mentioned above that plays an important role in the damage reduction effect, these two shapes have no absolute advantage, especially the Elliptical-2 (shown in Table 6). The mean value $\left(\bar{K}_{l}\right)$ of $S_{n}$ for the Elliptical-2 is as high as the $4^{\text {th }}$ position, which is only lower than the Rhombic. Although the $S_{m}$ value of Elliptical-2 is not so bad and has a certain improve on the damage reduction effect, it is not enough to explain the excellent performance of Circular and Elliptical-2 on the damage reduction effect. Furthermore, according to the Table 6, the $S_{n}$ and $S_{m}$ value of Square is not the biggest, but its damage reduction effect $(\mathrm{Q})$ is in the last place $\left(5^{\text {th }}\right)$.

The reason can be explain by the distribution state of contact pressure on the fitting surface. Thus, the contact pressure analysis of four different shape texture units is carried out, and the results are shown in the Fig. 8. Among them, Ellipse-1 and Ellipse-2 are classified into one class(Ellipse) because there is no different for the contact pressure analysis between them. The four texture units have the same equivalent circle diameter $(100 \mu \mathrm{m})$ and the same texture surface density (30\%). And the material parameters, constraints, loads and element methods of the four texture units are set the same value when analyzed.

At a load of $100 \mathrm{MPa}$, the surface contact pressure is lower in the middle surfaces of texture units and higher in the edges of the pit. During disassembly slipping, the edge areas will emerge an intense friction. And the degree of disassembly damage is positive to the area ratio of large contact pressure on the fitting surface. To get the area ratio, the contact pressure is distinguished into ' $<140 \mathrm{MPa}$ ', '140 170 MPa', '170 200 MPa' and '>200 MPa' four 
grades.

Statistical results show that the area ratio of '>200MPa' $\quad\left(P_{>200 M P a-R}\right)$ of Ellipse texture unit is $3.01 \%$, which is the lowest among the four units, while the value of square is the largest. And the $P_{>200 M P a-R}$ value of Circular is $4.52 \%$, listed in the $2^{\text {nd }}$ place. Moreover, the values of the minimum contact pressure $\left(P_{\text {min-V }}\right)$ are $91.62 \mathrm{MPa}$ (Ellipse, $\left.1^{\text {st }}\right), 105.09 \mathrm{MPa}$ (Circular, $\left.2^{\text {nd }}\right), 121.58 \mathrm{MPa}$ (Square, $3^{\text {rd }}$ ) and $123.4 \mathrm{MPa}$ (Rhombic, $4^{\text {th }}$ ). This explains why the disassembly damage reduction ability of Ellipse and Circular is better than Square, although they do not have an absolute advantage in their $S_{n}$ and $S_{m}$ values.

For the difference of damage reduction effect between Ellipse-1 and Ellipse-2(shown in Fig.6c), it needs to be explained from their collection ability of abrasive. In the process of interference fit disassembly, the abrasive particles in the texture pit are not keeping still, which tend to move to the front end of pit under the disassembly motion and the push of new fallen particles(Fig. 9). Therefore, the size of the abrasive particles that have entered the pit will determine whether the new particles can fall into the pit.

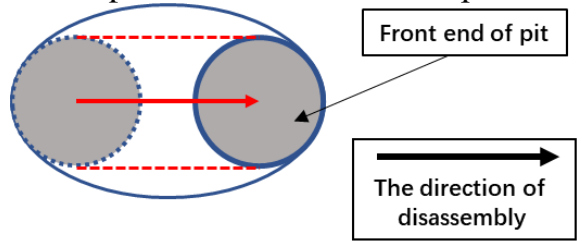

Figure 9 The movement trend of the particle in the texture pit

As shown in Fig.10, two circles with different sizes represent two abrasive particles with different diameters. If the small particle enter the pit earlier(Fig.10 a), it will occupy the front end gradually. When the larger abrasive particle meets the pit, the small particle will be forced to move under the extrusion effect of the larger one. Finally, the large and small particles can be caught by the pit together. In this case, Ellipse- 1 and Ellipse- 2 can be regarded as having the same particle collection ability.

If the large abrasive particle occupy the front end of the pit earlier(Fig.10 b), it is difficult to be pushed away from the front end of pit by the small one because the bottom of the pit is rough and the friction resistance is large. This makes the new smaller abrasive particle can be collected by Ellipse-1 easily but hard by Ellipse-2. So in this case, the particle collection ability of Ellipse-1 is better than that of Ellipse-2. This gives the reason why the damage reduction ability of Ellipse- 1 and Ellipse- 2 is very close, but the former is slightly higher than the latter. (Fig.6 c).

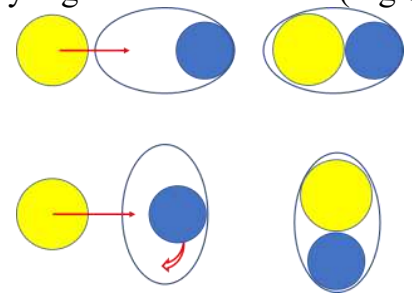

a) Small particle occupies the front end of the pit earlier;

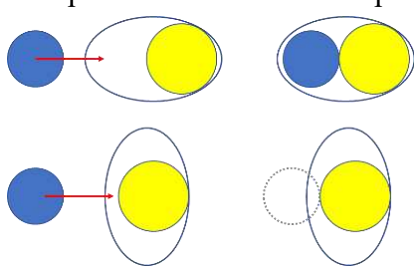

b ) Big particle occupies the front end of the pit earlier;

Figure10 Comparison of particle collection ability between Ellipse-1 and Ellipse-2

\section{Load-carrying capacity of interference fit with excellent damage reduction texture}

Although the disassembly damage of interference fit can be greatly reduced by adding pit texture, the primary service requirement is the load-carrying capacity for an interference fit.

Generally, for a pair of interference-fit parts, the texture added on the mating surface does not change the nominal contact pressure $(P)$ on the mating surface or the dimensions of the fitting parts $\left(d_{f}\right)$. So, according the contents of 2.1 , the load-carrying of interference-fit with the excellent damage reduction texture is closely related to the maximum static friction coefficient $(\mu)$ of the mating surface.

In order to compare the load-carrying capacity of the excellent damage reduction textured surface with that of the non-textured surface, 14 groups of load-carrying capacity simulation experiment are carried out. Each group contains 3 pairs of upper and lower specimens. Among which, 1 7 group are non-textured specimens and 8 14 group are specimens with excellent texture. The maximum static friction coefficients $(\mu)$ are measured as shown in Fig. 11.

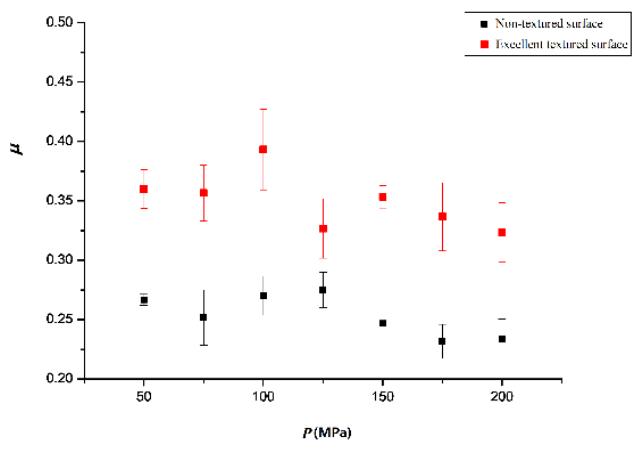

Figure11 Comparison of static friction coefficient

It shows that within the pressure $(P)$ range of $50 \sim 200$ $\mathrm{MPa}$, the static friction coefficients $(\mu)$ of excellent textured surface increase about 0.1 , and the range of increase is close to $40 \%$, which means the load-carrying capacity is increased synchronously.

The contrast experiments in Fig.11 are based on the surface of the new grinding specimens. The measured static 
friction coefficient $(\mu)$ represents the load-carrying of the new product.

After disassembly, the state of textured surface will be changed due to the dry friction between the interfaces. In order to explore the change of the load-carrying capacity for the mating surface of interference fit after reassembly, a comparative experiment is carried out for the excellent textured specimens. Within the pressure $(P)$ range of $50 \sim 150$ $\mathrm{MPa}$, a serial of three times load-carrying capacity experiment for the same pair of upper and lower specimens is carried out. That is to say, for the same pair of specimens, the values of static friction coefficient $(\mu)$ in 3 different states are measured respectively, which are the $\mu$ for "initial textured surface", "textured surface after once disassembly" and "textured surface after twice disassembles".

As shown in Fig.12, the static friction coefficient $(\mu)$ of texture surface decreases with the increasement of disassembly times within the pressure $(P)$ range of $50 \sim 150$ MPa. After twice disassembly, the static friction coefficient $(\mu)$ is still higher than that of the non-textured surface, but the difference is no longer significant.

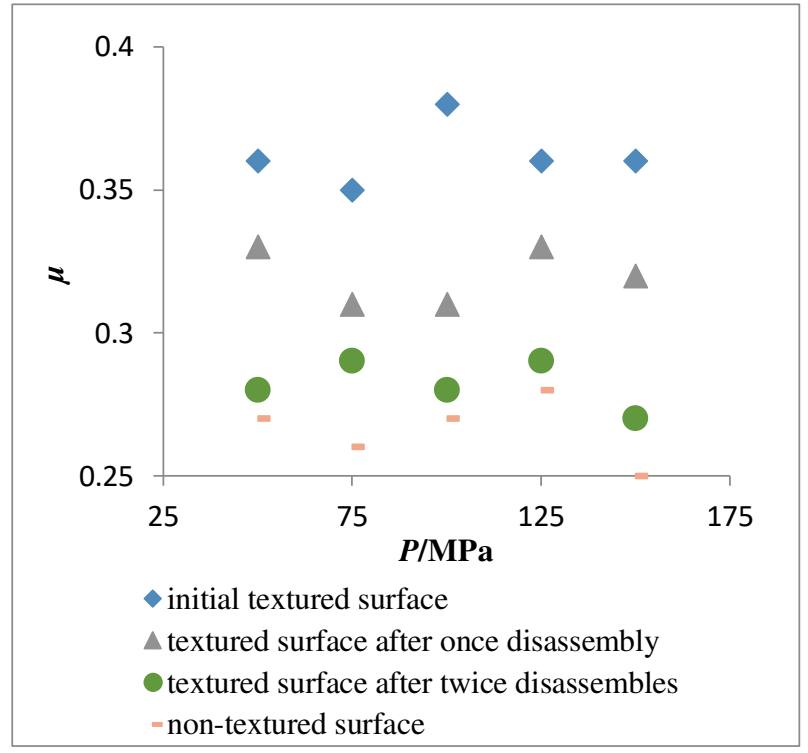

Figure 12 The maximum static friction coefficient $(\mu)$ of surface in 4 states

Fig.13 shows the photos of excellent textured surface before disassembly, after once disassembly and after twice disassembly. It can be seen that there are a series of microscopic scratches parallel to the direction of the disassembly on the surface of the specimen after disassembly. With the increasing of disassembly times, the annular melting zone around the pits is gradually broken, and the amount of abrasive debris in the pits increases gradually. The abrasive debris is the particles shed from the disassembly surface because of dry friction between the disassembly sliding surfaces.

According to the Fig.13c), the annular melting zone is broken severely after twice disassembly. And the value of $\mu$ is decreased a lot and closed to the non-textured surface at the same time. So, there may be some close relationship between the annular melting zone and the increase of load-carrying capacity.

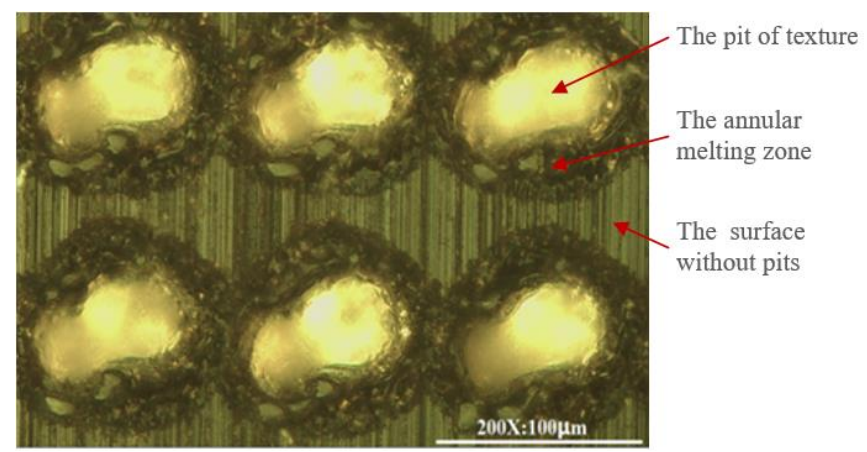

(a) Initial textured surface before disassembly

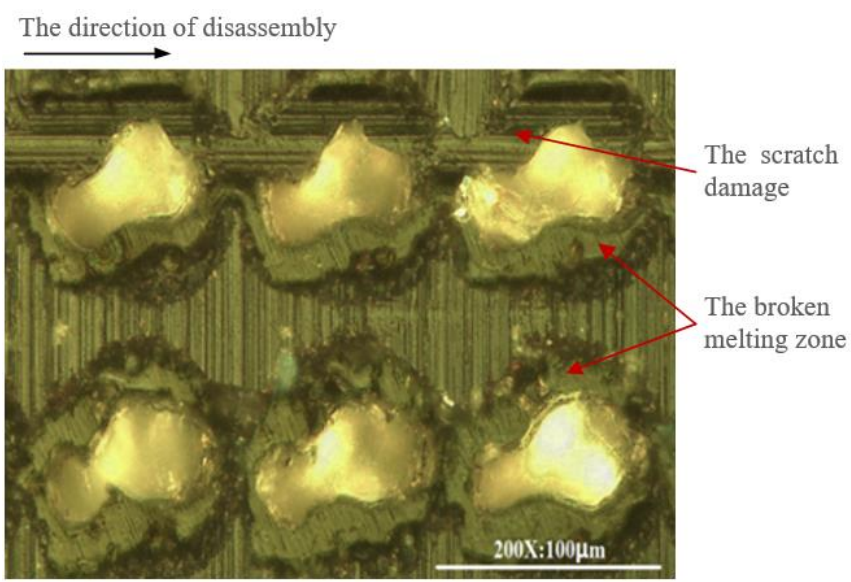

(b) Textured surface after once disassembly

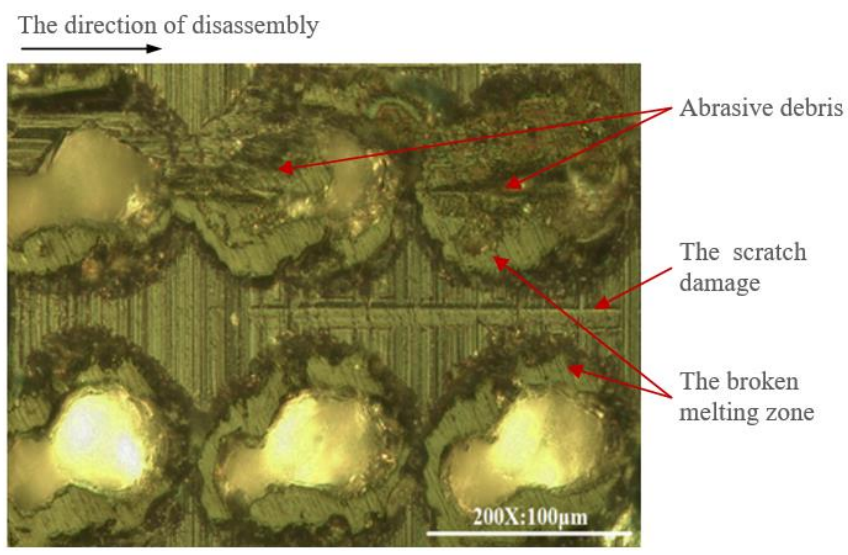

(c) Textured surface after twice disassembles

Figure 13 Microphotograph of the excellent textured surface before and after disassembly

\section{Conclusions}

During the process of remanufacturing disassembly, interference fit parts are difficult to be separated without damage because of the dry friction between the mating 
surface. In order to reduce the damage, 5 shapes of pit array textures are produced on the fitting surface. The damage reduction mechanism of textured surface and the load-carrying capacity of the excellent texture are studied through disassembly experiments and load-carrying capacity experiments. According to the experimental results, the following conclusions are obtained:

1. The order of influence of texture parameters on disassembly damage is as follows: single texture equivalent circle diameter $>$ texture shape $>$ texture surface density. The effect of single texture equivalent circle diameter and texture shape is obviously higher than that of texture surface density.

2. The excellent texture for interference fit is determined to be a kind of circular texture with a surface density of $30 \%$ and a diameter of $100 \mu \mathrm{m}$. The damage evaluation value $(Q)$ of the excellent textured surface is 0.25 , which is much smaller than that of the non-textured surface.

3. The reason of the excellent texture can effectively reduce disassembly damage is because of its outstanding particles collection capacity and the low probability of damage formation and evolution on the part of surface without pits. The particles collection capacity is mainly affected by two aspects: the total particle collection capacity of textured surface and the effective collection size of single texture pit. The damage formation and evolution probability on the part of surface without pits is closely related to three elements: the area of without pits zone in the non-textured $\operatorname{row}\left(S_{n}\right)$, the area of without pits zone in the textured row $\left(S_{m}\right)$ and the area ratio of large contact pressure on the fitting surface.

4. As the static friction coefficient $(\mu)$ of the excellent textured surface is increased about 0.1 than that of the non-textured surface within the contact pressure range of 50 $200 \mathrm{MPa}$ on the mating surface, the excellent texture has a significant increasing effect on the load-carrying capacity. And the increasing effect still exists even after twice disassembly process. And there is a close connection between the annular melting zone around texture and the load-carrying capacity of the interference fit.

\section{Declaration}

\section{Funding}

supported by the National Natural Science Foundation of China [grant No. 51635010].

\section{Availability of data and materials}

The datasets supporting the conclusions of this article are included within the article.

\section{Authors' contributions}

The author' contributions are as follows: Dan Zhou was in charge of the whole trial; Yi Xu wrote the manuscript; Xin
Gao assisted with sampling and laboratory analyses.

\section{Competing interests}

The authors declare no competing financial interests.

\section{Consent for publication}

Not applicable

\section{Ethics approval and consent to participate \\ Not applicable}

\section{References}

[1] Li, E. C., Shi, P. J., Xu, B. S., Analysis and Reflection on the policies and regulations of remanufacturing in China, Journal of Mechanical Engineering. 51(2015)117-123.

[2] Yusop, N. M., Wahab, D. A., (2016)Saibani, N., Realising the automotive remanufacturing roadmap in Malaysia: challenges and the way forward, Journal of Cleaner Production. 112(2016) 1910-1919 .

[3] Biao, S. U., Huang, X. Ren, Y., Research on Selective Assembly Method Optimization for Construction Machinery Remanufacturing Based on Ant Colony Algorithm, Journal of Mechanical Engineering. 53(2017) 60-68.

[4] Kernbaum, S., Heyer, S., Chiotellis, S., Process planning for IT-equipment remanufacturing, Journal of Manufacturing Science \& Technology. 2(2010)13-20.

[5] Yu, B., Wu, E., Chen, C., A general approach to optimize disassembly sequence planning based on disassembly network: A case study from automotive industry, Advances in Production Engineering \& Management. 12(2017) 305-320.

[6] Wang, J., Kang, J., Tang, L., Theoretical and experimental studies for wind turbine's shrink disk, Archive Proceedings of the Institution of Mechanical Engineers, Part C Journal of Mechanical Engineering Science. 229(2014) 325-334.

[7] Yang, G. M., Coquille, J. C., Fontaine, J., F., Contact pressure between two rough surfaces of a cylindrical fit, Journal of Materials Processing Tech. 123(2002) 490-497.

[8] M. Shulzhenko. Numerical Analysis of Induction Heating-Based Assembly and Disassembly of Shrink Fits[J]. Acta Technica sav, 2003, 49:169-183.

[9] Wang F , Zhang S, Hao S, et al. The Nondestructive Disassembly Method of Interference Fit of Sleeve-Base Structure in the Case of Cooling Excitation[M]// Sustainable Design and Manufacturing 2019

[10] Shen J , Rao S L, Liu G F , et al. FEM Analysis of Hydraulic Dismantling Feasibility on Shaft-Sleeve Interference Fits[J]. Advanced Materials Research, 2013, 712-715(2):1116-1121.

[11]Zhou, D., Lan, S., Gao, X., Huang, H. H., Liu, G. F., Nondestructive 
Surface Threshold Definition for Remanufacturing Disassembly of Interference Fit [J]International Journal of Precision Engineering and Manufacturing. 19(2018)1735-1743.

[12] WEN S. Z., Principles of Tribology ,Fourth Edition, Bei Jing, 2012.

[13]Evans, C. J., Bryan, J. B., "Structured", "Textured" or "Engineered" Surfaces, Cirp Annals. 48(1999)541-556.

[14]Zhan, J., Yang, M., Investigation on dimples distribution angle in laser texturing of cylinder-piston ring system, Tribology Transactions. 55(2012)693-697.

[15]Zhang, K., Deng, J., Xing, Y. S., Gao, L. H., Effect of microscale texture on cutting performance of WC/Co-based TiAlN coated tools under different lubrication conditions. Applied Surface Science. 326(2015)107-118

[16] Xiao, N., Khonsari, M. M., Thermal performance of mechanical seals with textured side-wall, Tribology International. 45(2012)1-7.

[17] Shukla, P., Waugh, D., Lawrence, J., Vilar, R., Laser surface structuring of ceramics, metals and polymers for biomedical applications: a review, Laser Surface Modification of Biomaterials: Techniques and Applications. 2016, 281-299.

[18] Xing, Y., Deng, J., Wu, Z., High friction and low wear properties of laser-textured ceramic surface under dry friction, Optics \& Laser Technology. 93(2017)24-32.

[19] Yue Z C . The Interference Fit for Centrifugal Compressor and The stress Analysis for Impeller Construction[J]. COMPRESSOR BLOWER \& FAN TECHNOLOGY, 1998.

[20] Li, X., Ma, W., Optimization for Mix Design of High-Performance Concrete Using Orthogonal Test. Communications in Computer \& Information Science. 232(2011)364-372.

[21]Han, S. L., Li, Z. Y., Gao. Y., Numerical study on die design parameters of self-pierce riveting process based on orthogonal test, Journal of Shanghai Jiaotong University(Science). 193(2014)08-312.

[22] ISO 25178-2:2012 Geometrical Product Specifications (GPS) - Surface texture: Areal, Part 2:Terms, definitions and surface texture parameters.

[23] ISMAIL S , SARANGI M . Hydrodynamic lubrication with deterministic micro textures consideringfluid inertia effect [J] .Tribology International,2014,69: 30-38 


\section{Figures}

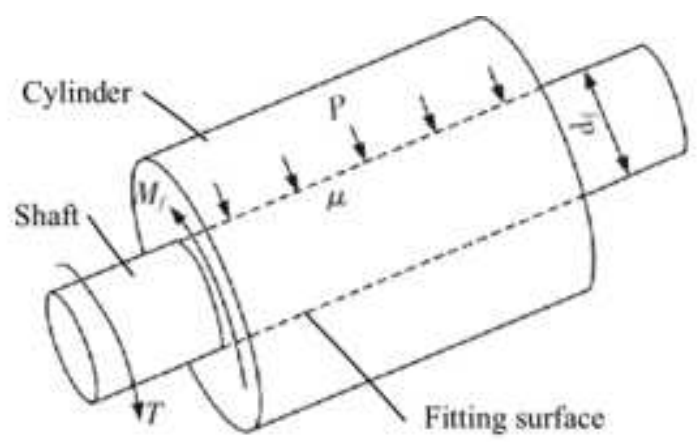

\section{Figure 1}

Interference fit model

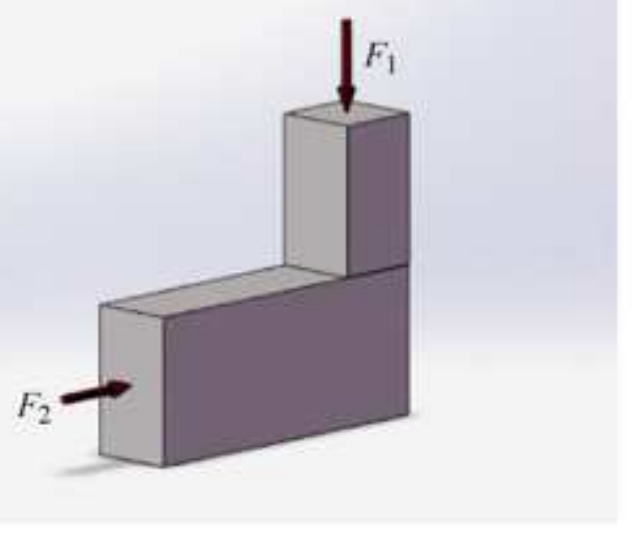

a) Disassembly damage simulation experiment

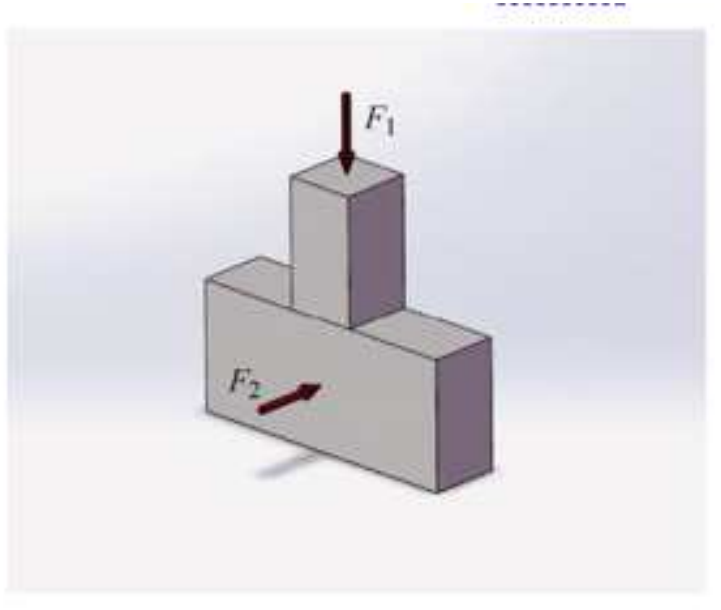

b) Load-carrying capacity simulation experiment

\section{Figure 2}

Simplified experiment model of interference fit (contact area: $10 \mathrm{~mm} \times 10 \mathrm{~mm}$; F1-the vertical force applied by experiment platform; F2-the horizontal force applied by experiment platform)

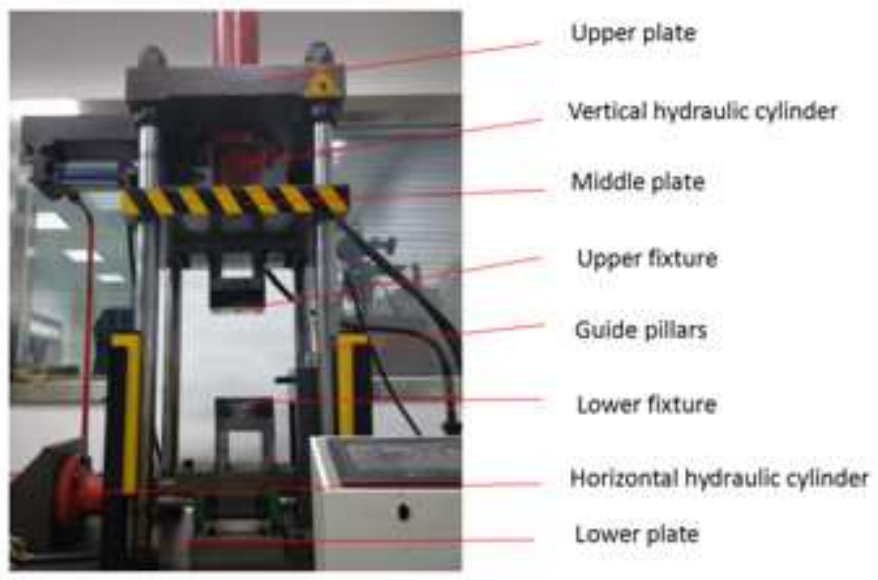

Figure 3 


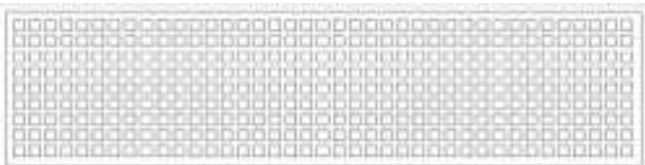

(a) Square texture

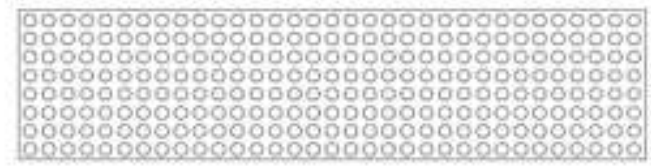

(b) Circular texture

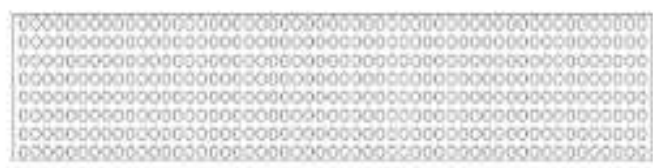

(c) Elliptical-1 texture

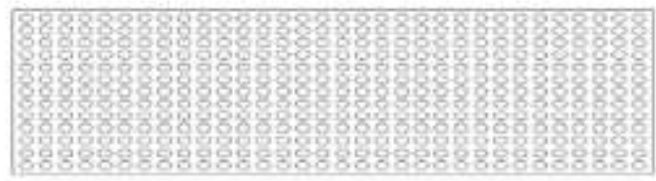

(d) Elliptical-2 texture

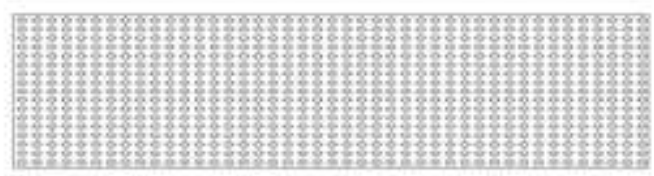

(e) Rhombic texture

\section{Figure 4}

Schematic diagram of the texture of different shape
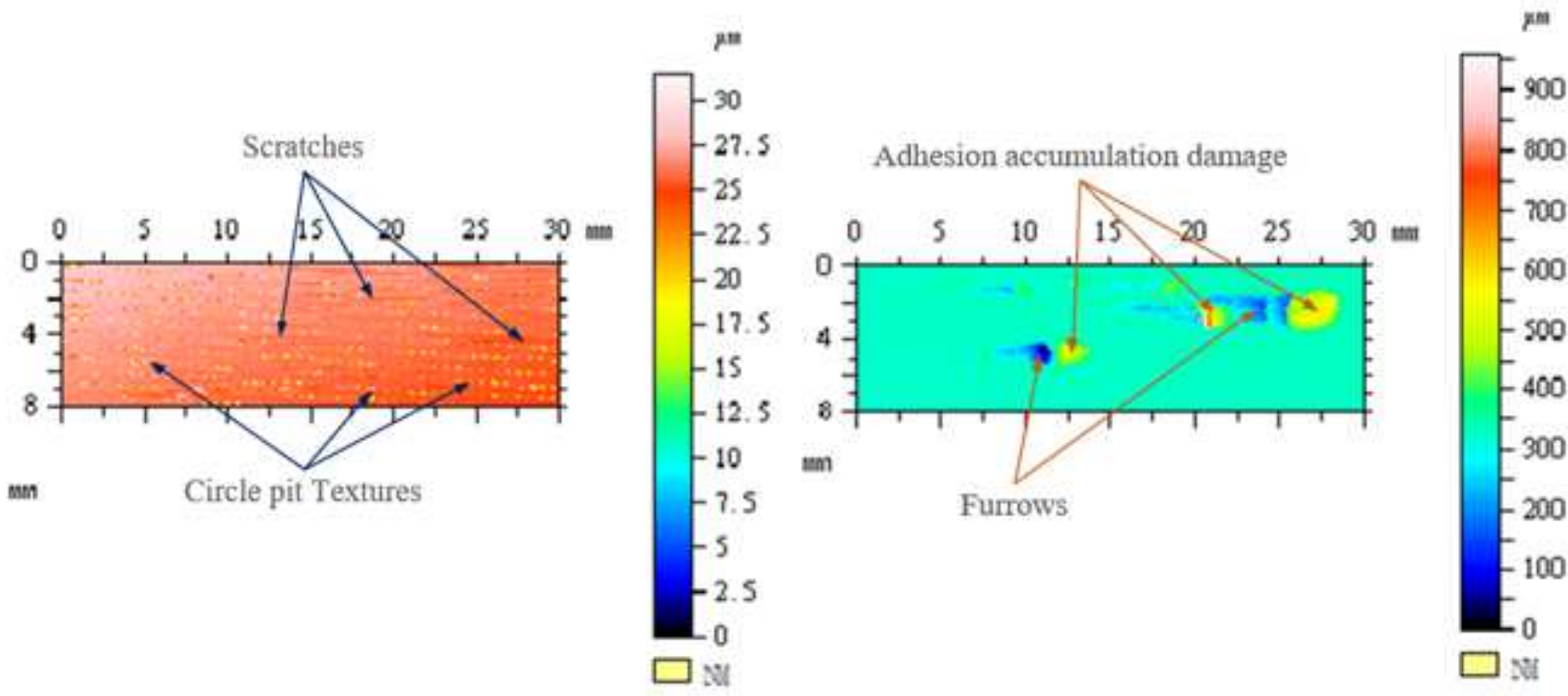

(a) Excellent textured specimen after once disassembly

(b) Non-textured specimen after once disassembly 


\section{Figure 5}

Surface topography image of disassembly damage

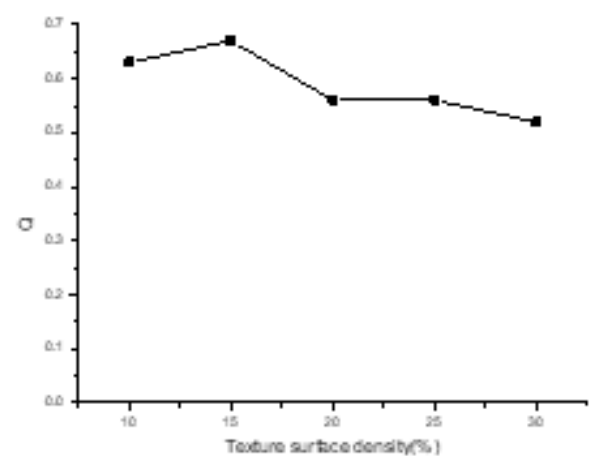

(a) Variation of $Q$ with texture surface density

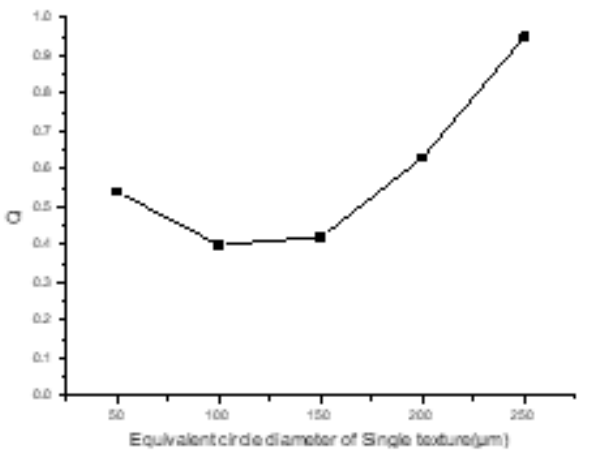

(b) Variation of $Q$ with the equivalent circle diameter of single texture

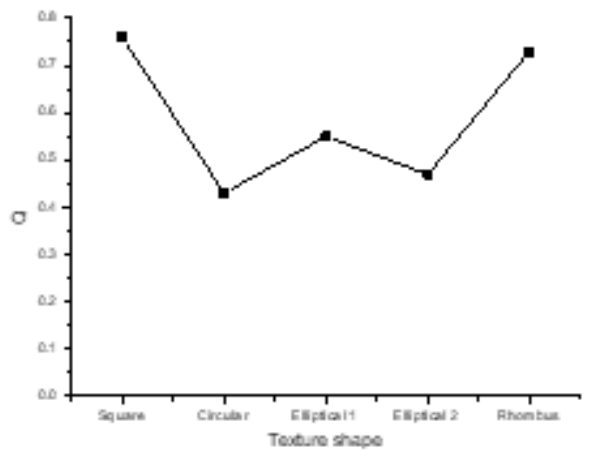

(c) Variation of $Q$ with the texture shape

\section{Figure 6}

Variation of comprehensive evaluation value of disassembly damage (Q) with 3 factors 

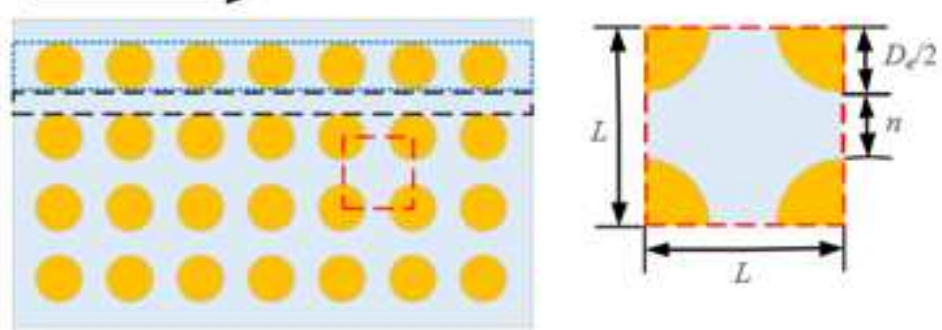

Without pits zone

Pits zone $\quad$

1

\section{Figure 7}

Diagram of textured surface and texture unit (Taking the circular texture as an example)

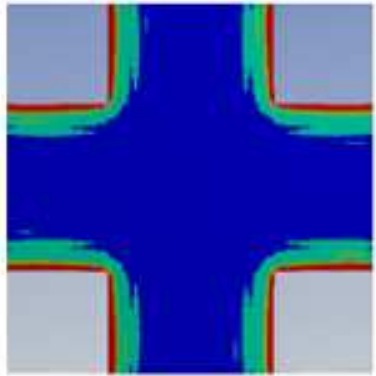

(a)

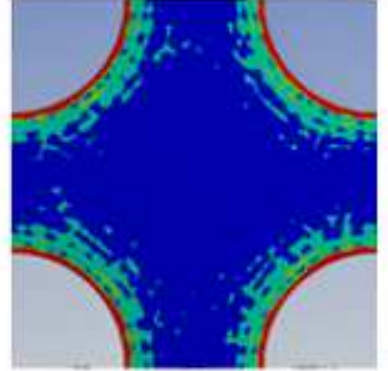

(b)

\section{MPa-170MPa}

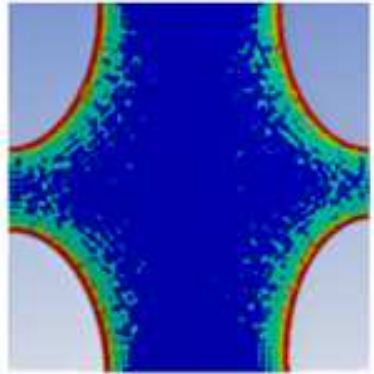

(c) $170 \mathrm{MPa}-200 \mathrm{MPa}$

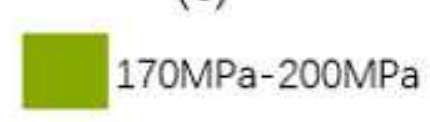

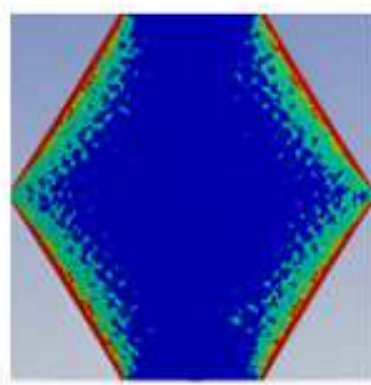

(d) Over $200 \mathrm{MPa}$

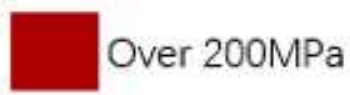

\section{Figure 8}

Contact pressure on the surface of texture units ( $\mathrm{a}$ - Square texture unit; $\mathrm{b}$ - Circular texture unit; c Elliptical texture unit; $d$ - Rhombic texture unit)

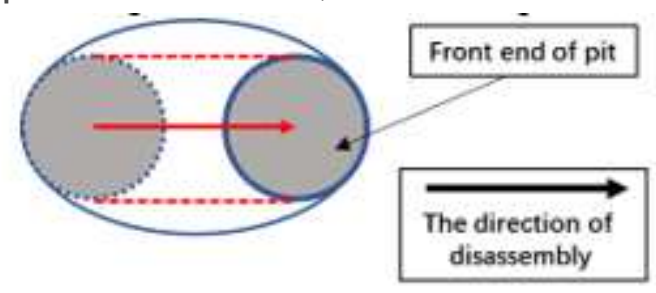

Figure 9

The movement trend of the particle in the texture pit 


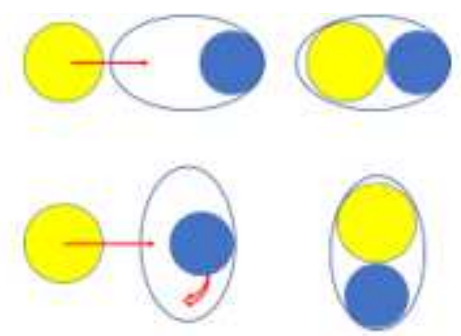

a) Small particle occupies the front end of the pit earlier;

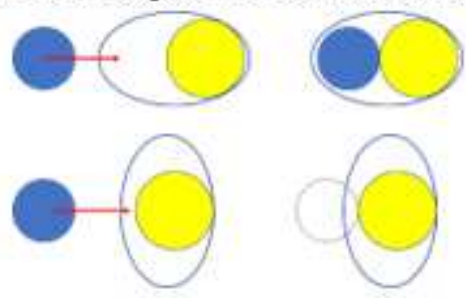

b) Big particle occupies the front end of the pit earlier;

Figure 10

Comparison of particle collection ability between Ellipse-1 and Ellipse-2

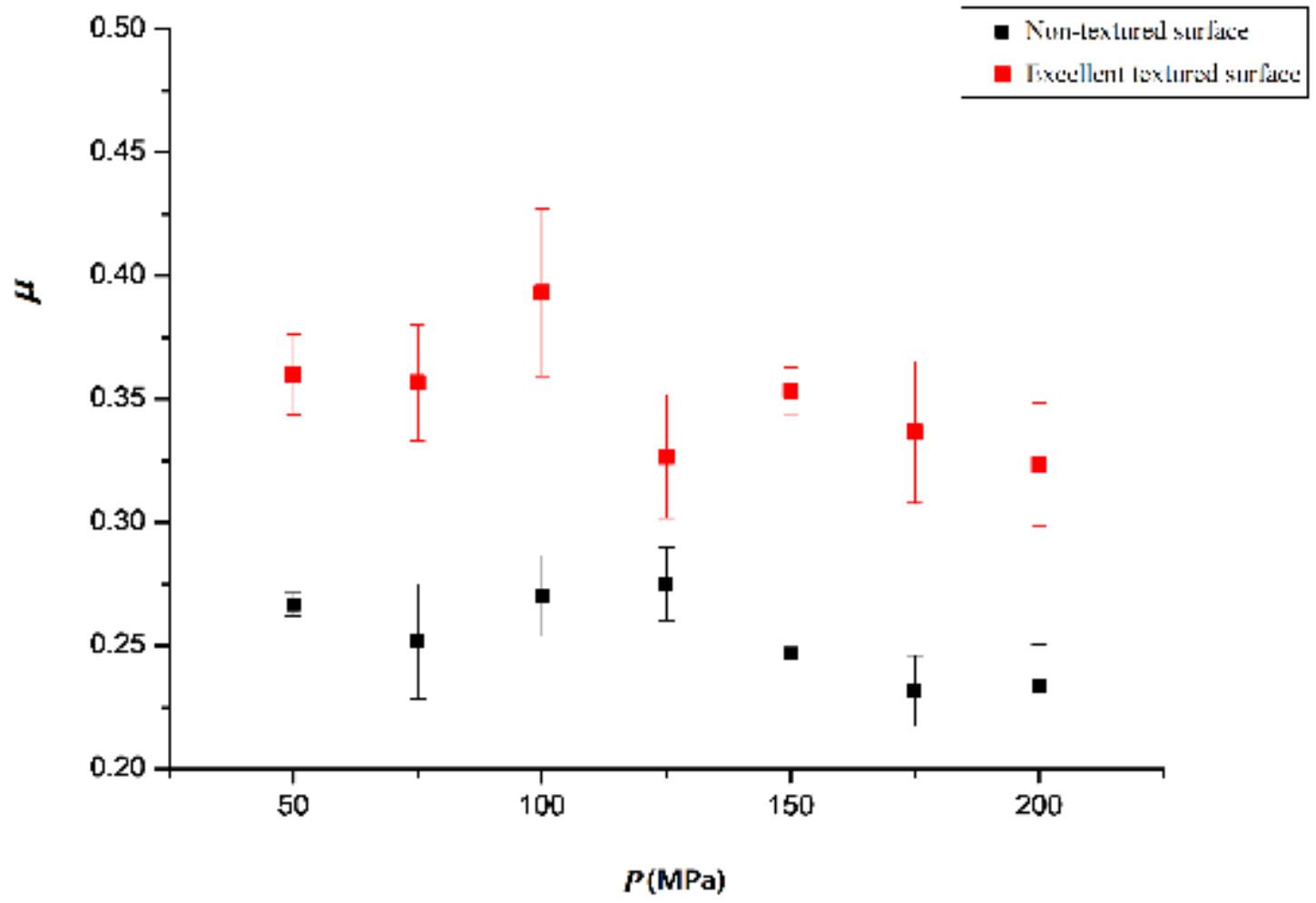

Figure 11

Comparison of static friction coefficient 


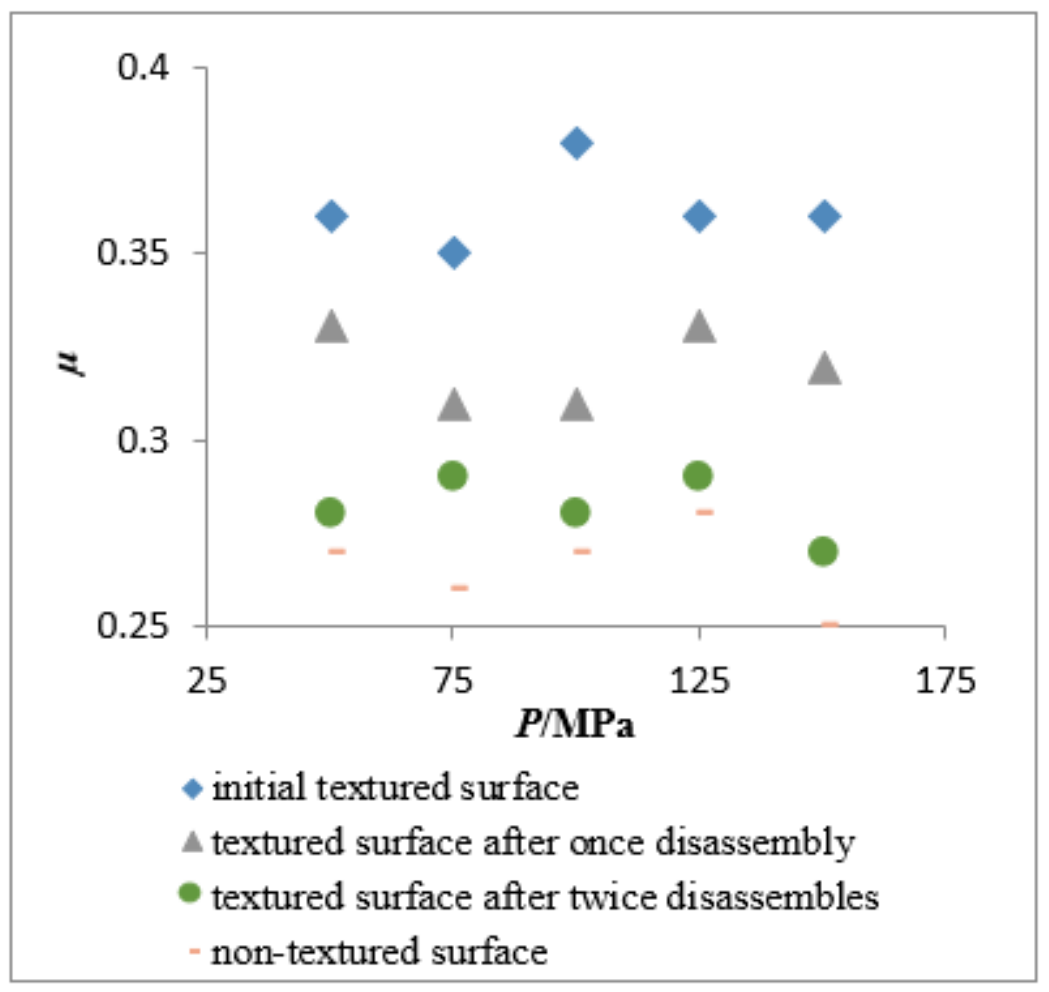

\section{Figure 12}

The maximum static friction coefficient $(\mu)$ of surface in 4 states

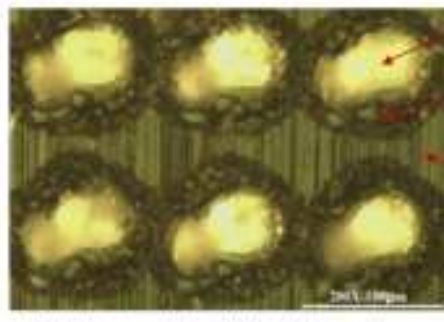

Thropt ef vestim

(a) Inisial textured nurface belore disassembly

The ditection ef diumendby

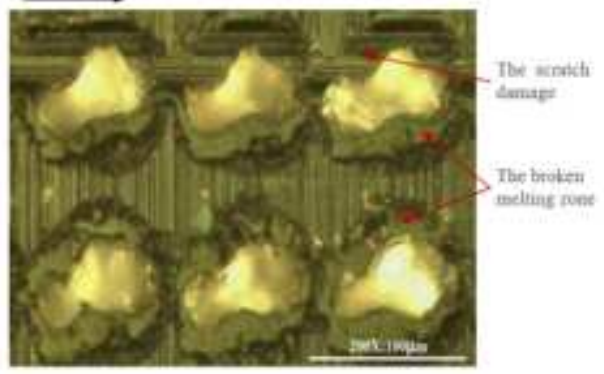

(b) Textured surface affer boce disassembly

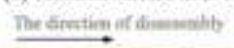

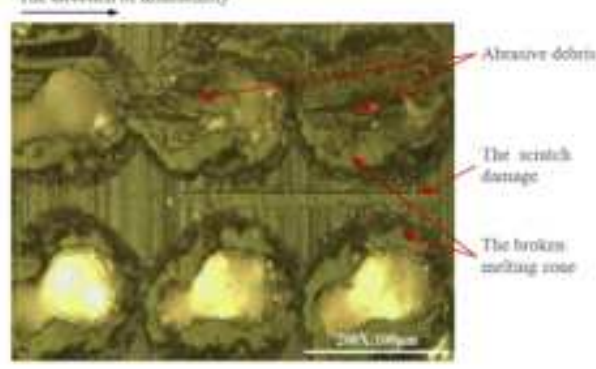

(c) Texamed waface after twice diussembles 
Figure 13

Microphotograph of the excellent textured surface before and after disassembly 